\title{
Urgences
}

\section{Jardin de pierres en octobre}

\section{Louise Blouin et Bernard Pozier}

Numéro 16, mars 1987

D.G. Jones : d'un texte, d'autres

URI : https://id.erudit.org/iderudit/025374ar

DOI : https://doi.org/10.7202/025374ar

Aller au sommaire du numéro

Éditeur(s)

Urgences

ISSN

0226-9554 (imprimé)

1927-3924 (numérique)

Découvrir la revue

Citer ce document

Blouin, L. \& Pozier, B. (1987). Jardin de pierres en octobre. Urgences, (16),

22-23. https://doi.org/10.7202/025374ar d'utilisation que vous pouvez consulter en ligne.

https://apropos.erudit.org/fr/usagers/politique-dutilisation/ 


\section{Louise Blouin/Bernard Pozier JARDIN DE PIERRES EN OCTOBRE}

Dans la pluie, c'est une ruine composée d'ombres, c'est

la tombe des fleurs

Le jardin recueille des couleurs mortes de feuilles. Et toujours ce sont les pierres qui fleurissent

comme une quantité de tomes où ceux qui sont partis continuent de parler

De plus en plus ma bouche s'emplit de pierres et les os de mes collègues

ressemblent aux fleurs

est-ce que ce chaos est le paradis ou Angkor Vat

ou encore le quartier des affaires désert après dix heures du soir?

Ce n'est ni vivant ni mort

ni humain. Je passe à côté du jardin dans la pluie, ténébreux. Sur les pierres naissent des runes. 
ROCK GARDEN? Est-ce un nom de lieu, quelque part en Estrie, comme Rock Forest? Cela aurait pu aussi être le Jardin du Rock, mais non! Pourtant ROCKGARDEN était le nom d'un groupe des années soixante-dix, tout comme Octobre d'ailleurs.

IT IS A RUIN OF SHADOW, une ruine d'ombres, on serait tenté de faire de ce «de» un complément du nom, et de dire à l'envers du poème, CELA DÉFAIT LES OMBRES. Comme tout de suite on a envie de prendre le tombeau des fleurs dans un sens figuré et de dire C'EST LA FIN DES FLEURS, mais cela détruirait le jeu sonore tomb/tomes.

Nous avons vraiment envie que les couleurs des feuilles tombées soient en français des COULEURS MORTES DE FEUILLES.

A GATHERING OF TOMES nous suggère un paquet de gros livres, en imaginant que tous ceux-ci se rattachent à la même histoire, nous songeons à les remplacer par COMME DES ROMANS-FLEUVES, mais encore une fois ce serait trahir le son du poète.

ANGKOR WAT nous amène à ajouter OU ENCORE juste pour le son. Et cela nous mène jusqu'à THE INNER CITY qu'on a envie de traduire par le COEUR DE LA VILLE, mais une telle expression aurait en fait un sens contraire en anglais et en français, nous y verrions alors vie, animation et plaisir, et non pas mort et désolation. Cette constatation nous parvient de l'éclairage de Judith Cowan qui nous a aussi parlé du jardin de pierres de Jones, de ses fleurs mortes et des pierres qui deviennent colorées et rutilantes sous la pluie.

A GROWTH OF RUNES, sans doute HIÉROGLYPHES dirait-il mieux en français le caractère mystérieux des messages du jardin, encore une fois, le son aura orienté notre choix. 